\title{
Diminishing Surgical Site Infections in Australia: Time Trends in Infection Rates, Pathogens and Antimicrobial Resistance Using a Comprehensive Victorian Surveillance Program, 2002-2013
}

\author{
Leon J. Worth, MBBS, FRACP; Grad Dip Epi, PhD; Ann L. Bull, PhD, M.App.Epid; Tim Spelman, BSc, MBBS; \\ Judith Brett, BN; Michael J. Richards, MBBS, FRACP, MD
}

овJестіVE. To evaluate time trends in surgical site infection (SSI) rates and SSI pathogens in Australia.

DESIGN. Prospective multicenter observational cohort study.

Setting. A group of 81 Australian healthcare facilities participating in the Victorian Healthcare Associated Infection Surveillance System (VICNISS).

PAtients. All patients underwent surgeries performed between October 1, 2002, and June 30, 2013. National Healthcare Safety Network SSI surveillance methods were employed by the infection prevention staff at the participating hospitals.

Intervention. Procedure-specific risk-adjusted SSI rates were calculated. Pathogen-specific and antimicrobial-resistant (AMR) infections were modeled using multilevel mixed-effects Poisson regression.

RESULTS. A total of 183,625 procedures were monitored, and 5,123 SSIs were reported. Each year of observation was associated with $11 \%$ risk reduction for superficial SSI (risk ratio [RR], 0.89; 95\% confidence interval [CI], 0.88-0.90), 9\% risk reduction for deep SSI (RR, 0.91; 95\% CI, $0.90-0.93$ ), and 5\% risk reduction for organ/space SSI (RR, 0.95; 95\% CI, 0.93-0.97). Overall, 3,318 microbiologically confirmed SSIs were reported. Of these SSIs, 1,174 (35.4\%) were associated with orthopedic surgery, 827 (24.9\%) with coronary artery bypass surgery, 490 (14.8\%) with Caesarean sections, and $414(12.5 \%)$ with colorectal procedures. Staphylococcus aureus was the most frequently identified pathogen, and a statistically significant increase in infections due to ceftriaxone-resistant Escherichia coli was observed (RR, 1.37; 95\% CI, 1.10-1.70).

CONCLUSIONS. Standardized SSI surveillance methods have been implemented in Victoria, Australia. Over an 11-year period, diminishing rates of SSIs have been observed, although AMR infections increased significantly. Our findings facilitate the refinement of recommended surgical antibiotic prophylaxis regimens and highlight the need for a more expansive national surveillance strategy to identify changes in epidemiology.

Infect Control Hosp Epidemiol 2015;36(4):409-416

Surgical site infections (SSIs) are healthcare-associated infections (HAIs) that contribute significantly to adverse clinical outcomes and increased healthcare costs. ${ }^{1}$ Reported rates vary according to surgical procedure, spanning $<1 \%$ for clean procedures ${ }^{2}$ to $30 \%$ for some colorectal procedures. ${ }^{3-6}$ Standardized surveillance has long been recognized as a minimum and necessary requirement for effectual prevention strategies, ${ }^{7-9}$ and diminishing SSI rates have been noted following the implementation of surveillance programs. ${ }^{10}$ Surveillance data have recently been used to evaluate appropriateness of surgical antimicrobial prophylaxis in the United States. $^{11}$

In Australia, national guidelines for surgical antibiotic prophylaxis are widely available. ${ }^{12}$ However, evaluation of pathogen-specific data concerning infections complicating the range of surgical procedures has not been performed to determine whether guidelines are concordant with local epidemiology.
In 2002, the Victorian Healthcare-Associated Infection Surveillance System (VICNISS) commenced monitoring of SSIs. ${ }^{13,14}$ The objectives of this study were (1) to examine rates of SSIs according to operative procedure groups and (2) to analyze trends over time for SSI rates, pathogens responsible for SSIs, and antimicrobial susceptibility of pathogens responsible for SSIs in Victorian hospitals for the period October 1, 2002, to June 30, 2013.

\section{METHODS}

The VICNISS program was established to monitor a range of HAI processes and outcomes in Victorian hospitals, including SSIs. ${ }^{15}$ The SSI surveillance module is based on the National Healthcare Safety Network (NHSN), Centers for Disease Control and Prevention (CDC). ${ }^{16,17}$ For the current study,

Affiliation: Victorian Healthcare Associated Infection Surveillance System (VICNISS) Coordinating Centre, Melbourne, Victoria, 3000, Australia.

Received July 16, 2014; accepted November 30, 2014; electronically published January 20, 2015

(C) 2015 by The Society for Healthcare Epidemiology of America. All rights reserved. 0899-823X/2015/3604-0006. DOI: 10.1017/ice.2014.70 
data collected between October 1, 2002, and June 30, 2013, were analyzed.

\section{Participating Hospitals}

During the study period, all large Victorian public hospitals participated in the VICNISS program. Hospitals were required to monitor at least 2 surgical procedure groups for each 12-month period, with continuous surveillance mandated for coronary artery bypass graft (CABG) procedures and for $\mathrm{hip} / \mathrm{knee}$ arthroplasty procedures if $>50$ procedures were performed annually. Submission of data for other procedures and participation by private hospitals was voluntary.

\section{Definitions}

Consistent with NHSN/CDC criteria, ${ }^{16}$ SSIs were classified as superficial, deep, or organ/space. Microbiologically confirmed SSIs associated with the following operative procedure groups were analyzed: (1) CABG with both chest and donor site incisions or CABG with chest incision only, (2) Caesarean section, (3) hip and knee prostheses, (4) colorectal surgery, (5) other abdominal surgery (eg, gastric surgery, cholecystectomy, herniorrhaphy, appendectomy, or small bowel surgery), (6) cardiac surgery (non-CABG), (7) hysterectomy (abdominal or vaginal), and (8) vascular surgery.

Patients were monitored for signs of SSI until discharge from the acute-care facility. If patients were readmitted to the hospital with SSI within 12 months of the procedure, these infections were recorded. SSI rates were calculated by dividing the number of SSIs by the number of specific operative procedures and multiplying the results by 100 . Risk-indexing was performed according to NHSN methodology. ${ }^{17,18}$

\section{Data Collection and Validation}

Data were collected by infection prevention staff affiliated with participating healthcare facilities. All were trained regarding case definitions and surveillance methods by VICNISS Coordinating Centre staff. When a pathogen was isolated, the organism and antimicrobial susceptibilities were recorded using reported antimicrobial breakpoints (ie, susceptible, resistant, or intermediate susceptibility). All data were submitted via a standardized data collection tool, with electronic data submission available from 2010. Prospective monitoring was performed using patient records and microbiology and radiology results.

\section{Reporting and Statistical Analysis}

Multilevel mixed-effects Poisson regression was used to model counts of pathogen-specific SSIs for procedure categories where the aggregate number of procedures per time period formed the exposure. In the absence of explicit data regarding individual hospital characteristics (eg, case mix), the hospital identifier was modeled as a random effect. Effect size was quantified as the risk ratio (RR). A linear relationship between SSI count and time variables was assumed. The validity of this assumption was confirmed by comparing a base linear Poisson model with alternate nonlinear quadratic and cubic relationships using analysis of residual plots, a likelihood ratio test, and assessment of adjusted coefficient of determination $\left(\mathrm{R}^{2}\right)$. In each instance, residuals were minimized and $\mathrm{R}^{2}$ was maximized in the linear model compared to either quadratic or cubic models.

Analysis was confined to pathogen and procedure categories for which sufficient annual data were available. Given a limited number of events for some pathogens, detailed analysis was restricted to the 6 most highly ranked SSI pathogens. In all instances, $P<0.05$ was considered significant. Analysis was undertaken using Stata version 13 (StataCorp, College Station, Texas).

\section{Ethics Review}

No patient-identifying data were captured for the purposes of the study, and all hospital-level data were deidentified. This study was a quality-assurance audit without direct impact upon patient care; therefore, an ethics review was not required.

\section{RESULTS}

Between October 1, 2002, and June 30, 2013, a total of 183,625 procedures (164,721 patients) were monitored and 5,123 SSIs were reported, corresponding to an overall crude SSI rate of 2.8 per 100 procedures. Of these, 3,318 (64.8\%) were microbiologically confirmed SSIs. A total of 81 healthcare facilities participated in surveillance activities. Of patients with infection, 2,942 (57.4\%) were female and 2,164 (42.2\%) were male (patient sex was not recorded in 17 instances). Median (IQR) age at surgery was 63 years (range, $40-74$ years).

\section{Trends in SSI Rates}

Across all procedures and SSI categories, every 1-year increase across the observation period was associated with a $9 \%$ decrease in the risk of SSI (RR 0.91, 95\% confidence interval [CI] 0.90-0.92). Of the 5,123 SSIs, 2738 (53.5\%) were superficial, $1,210(23.6 \%)$ were deep incisional, and 1,174 (22.9\%) were organ/space infections, corresponding to $1.49,0.66$, and 0.64 infections per 100 procedures, respectively. Significant reductions in SSI were observed for all infection categories: every 1-year increase across the observation period was associated with an $11 \%$ decrease in the risk of superficial SSI (RR, 0.89; 95\% CI, 0.88-0.90), a 9\% decrease in the risk of deep SSI (RR, 0.91; 95\% CI, 0.90-0.93), and a 5\% decrease in the risk of organ/space SSI (RR, 0.95; 95\% CI, 0.93-0.97).

Crude SSI rates (per 100 procedures) were highest for vascular surgical procedures $(11.79 ; 95 \% \mathrm{CI}, 8.70-15.64)$ and lowest for hysterectomies (2.01; 95\% CI, 1.68-2.39). Colorectal procedures were associated with a crude SSI rate of 8.67 per 100 procedures ( $95 \%$ CI $8.06-9.31)$. Table 1 provides the 
T A B LE 1. Surgical Site Infections (SSIs) in Victorian Patients, by National Healthcare Safety Network (NHSN) Risk Index (2002-2013)

\begin{tabular}{|c|c|c|c|c|c|c|c|c|}
\hline \multirow[b]{2}{*}{ Risk Index $^{\mathrm{a}}$} & \multicolumn{8}{|c|}{ No. of SSIs/No. of Procedures (SSI incidence per 100 procedures, 95\% CI) } \\
\hline & $\mathrm{CABG}^{\mathrm{b}, \mathrm{c}}$ & $\begin{array}{l}\text { Caesarean } \\
\text { section }^{\mathrm{d}}\end{array}$ & $\begin{array}{l}\text { Hip/Knee } \\
\text { Prosthesis }^{c}\end{array}$ & Colorectal $^{\mathrm{d}}$ & $\begin{array}{c}\text { Other } \\
\text { Abdominal }^{\mathrm{d}, \mathrm{e}}\end{array}$ & $\begin{array}{c}\text { Cardiac } \\
(\text { Non-CABG })^{\mathrm{d}}\end{array}$ & Hysterectomy $\mathrm{d}, \mathrm{f}$ & Vascular $^{\mathrm{d}, \mathrm{g}}$ \\
\hline \multirow[t]{2}{*}{-1} & $0 / 0$ & $0 / 0$ & $0 / 0$ & $17 / 623$ & $24 / 3083$ & $0 / 0$ & $0 / 0$ & $0 / 0$ \\
\hline & $(0.00)$ & $(0.00)$ & $(0.00)$ & $(2.73,1.59-4.37)$ & $(0.78,0.50-1.16)$ & $(0.00)$ & $(0.00)$ & $(0.0$ \\
\hline \multirow[t]{2}{*}{0} & $1 / 139$ & $677 / 34,248$ & $309 / 18,831$ & $163 / 2858$ & $66 / 4738$ & $2 / 85$ & $44 / 3,474$ & $4 / 59$ \\
\hline & $(0.72,0.18-4.01)$ & $(1.98,1.83-2.13)$ & $(1.64,1.46-1.83)$ & $(5.70,4.86-6.65)$ & $(1.39,1.08-1.78)$ & $(2.35,0.29-8.50)$ & $(1.27,0.92-1.70)$ & $(6.78,1.85-17.36)$ \\
\hline \multirow[t]{2}{*}{1} & $691 / 16,567$ & $232 / 11,650$ & $737 / 27,908$ & $301 / 3,277$ & $61 / 1,697$ & $49 / 1,862$ & $32 / 2,034$ & $27 / 252$ \\
\hline & $(4.17,3.87-4.49)$ & $(1.99,1.74-2.27)$ & $(2.64,2.45-2.84)$ & $(9.19,8.18-10.28)$ & $(3.60,2.75-4.62)$ & $(2.63,1.95-3.48)$ & $(1.57,1.08-2.22)$ & $(10.71,7.06-15.59)$ \\
\hline \multirow[t]{2}{*}{2} & $425 / 5,996$ & $27 / 990$ & $299 / 7,647$ & $187 / 1,453$ & $24 / 350$ & $45 / 872$ & $21 / 479$ & $15 / 89$ \\
\hline & $(7.12,6.46-7.83)$ & $(2.73,1.80-3.97)$ & $(3.91,3.48-4.38)$ & $(12.87,11.09-14.85)$ & $(6.86,4.39-10$ & $(5.16,3.76-6.91)$ & $(4.38,2.71-6.70)$ & $(16.85,9.43-27.80)$ \\
\hline \multirow[t]{2}{*}{3} & $1 / 15$ & $0 / 17$ & $8 / 58$ & $33 / 152$ & $4 / 32$ & $2 / 35$ & $0 / 3$ & $0 / 1$ \\
\hline & $(6.67,0.17-37.14)$ & $(0.00)$ & $(13.79,5.95-27.18)$ & $(21.71,14.94-30.49)$ & $(12.50,3.41-32.00)$ & $(5.71,0.69-20.64)$ & $(0.00)$ & $(0.00)$ \\
\hline \multirow[t]{2}{*}{ Not recorded } & $19 / 421$ & $108 / 3,928$ & $100 / 2,059$ & $52 / 325$ & $99 / 1,093$ & $35 / 604$ & $34 / 514$ & $2 / 6$ \\
\hline & $(4.51,2.72-7.05)$ & $(2.75,2.26-3.32)$ & $(4.86,3.95-5.91)$ & $(16.00,11.95-20.98)$ & $(9.06,7.36-11.03)$ & $(5.80,4.04-8.06)$ & $(6.62,4.58-9.24)$ & $(33.33,4.04-120.41)$ \\
\hline \multirow[t]{2}{*}{ Unadjusted $^{\mathrm{h}}$} & $1137 / 23,108$ & $1044 / 50,833$ & $1453 / 5,6503$ & $753 / 8,688$ & 290/10,993 & $133 / 3,458$ & $131 / 6,504$ & $48 / 407$ \\
\hline & $(4.92,4.64-5.22)$ & $(2.05,1.93-2.18)$ & $(2.57,2.44-2.71)$ & $(8.67,8.06-9.31)$ & $(2.64,2.34-2.96)$ & $(3.85,3.22-4.56)$ & $(2.01,1.68-2.39)$ & $(11.79,8.70-15.64)$ \\
\hline
\end{tabular}

NOTE. CABG, coronary artery bypass graft; CI, confidence interval.

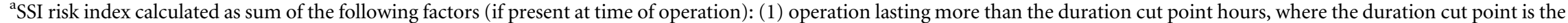
approximate 75th percentile of the duration of surgery in minutes for the operative procedure, (2) contaminated (class 3) or dirty/infected (class 4) wound class, and (3) American Society of Anaesthesiologists physical status classification of 3, 4, or 5. Risk index reduced by 1 unit if laparoscopic procedure performed. ${ }^{17}$

"Includes "chest and donor" and "chest only."

cContinuous surveillance performed at participating hospitals during the study period.

${ }^{\mathrm{d}}$ Periodic surveillance performed by selected hospitals during the study period.

${ }^{\mathrm{e}}$ Includes gastric surgery, cholecystectomy, herniorrhaphy, appendectomy, and small bowel surgery.

${ }^{\mathrm{f}}$ Includes abdominal and vaginal hysterectomies.

${ }^{\mathrm{g}}$ Includes femoropopliteal and femorotibial bypass, abdominal aortic aneurysm repair, and vascular surgery not otherwise specified.

hoverall (crude) data. 
number of monitored procedures and procedure-specific SSI rates by risk index. For procedures in which continuous surveillance was performed (CABG and orthopedic procedures), the majority were classified as risk index category 1 . SSI rates for risk index category 2 were $\sim 50 \%$ higher than rates for risk index category 1.

Of all microbiologically confirmed SSIs, $1,174(35.4 \%)$ were associated with orthopedic procedures, 827 (24.9\%) were associated with CABG, $414(12.5 \%)$ were associated with colorectal procedures, 131 (3.9\%) were associated with other abdominal surgeries, 490 (14.8\%) were associated with Caesarean sections, $87(2.6 \%)$ were associated with other cardiac procedures, $66(2.0 \%)$ were associated with hysterectomies, and $31(0.9 \%)$ were associated with vascular surgery.

\section{Trends in Pathogens Responsible for SSIs}

Table 2 demonstrates the relative frequency (ranking) of infecting pathogens according to surgical procedure group, based upon the 10 most frequent SSI pathogens for all procedures. Across all procedures, S. aureus was identified as the most frequent pathogen; it was responsible for $46.5 \%$ of microbiologically confirmed SSIs.

For SSIs following CABG and orthopedic procedures, Pseudomonas spp. were the second most frequently reported pathogen, and coagulase-negative staphylococci (CNS) were ranked third. Coagulase-negative staphylococci were responsible for $5.9 \%$ and $8.9 \%$ of microbiologically-confirmed SSIs following $\mathrm{CABG}$ orthopedic procedures, respectively.

Of pathogens responsible for SSI following colorectal procedures, $28.7 \%$ were $S$. aureus, and $46.2 \%$ of tested isolates were methicillin-resistant $S$. aureus (MRSA). Of pathogens responsible for SSI following abdominal procedures, $42.0 \%$ were S. aureus, and $23.4 \%$ of tested isolates were MRSA.

Modeled annual time trends for pathogen-specific SSIs are provided in Table 3. Across all procedures, every 1-year increase was associated with significant reductions in risk of $S$. aureus, Pseudomonas spp., and E. coli infections (risk reductions of $12 \%, 7 \%$, and $11 \%$, respectively). Whereas annual risks for SSIs due to the majority of pathogens diminished during the study period, CABG procedures were associated with a $14 \%$ annual risk increase for SSIs due to CNS.

Trends in Antimicrobial Resistance of Pathogens Responsible for SSIs

Table 4 summarizes the proportion of infecting S. aureus, Pseudomonas spp., E. coli, and Enterococcus spp. isolates with antibiotic resistance. Of all $S$. aureus isolates tested for vancomycin resistance $(n=1,131)$, no resistant or intermediate-resistant isolates were reported. Of all isolates tested for methicillin resistance, $31.6 \%$ were confirmed to be MRSA. Across all procedures, an $18 \%$ average annual risk reduction in SSI due to MRSA was observed.
Low rates of ciprofloxacin, gentamicin, and imipenem resistance were reported in Pseudomonas isolates responsible for SSIs $(0.49 \%, 0.48 \%$, and $0.84 \%$, respectively). Ceftazidime resistance was reported in $7.7 \%$ of Pseudomonas isolates, but no significant trend over time was demonstrated.

Of $E$. coli isolates responsible for SSIs, gentamicin resistance was reported in $7.6 \%$ of these cases, ciprofloxacin resistance was reported in $6.1 \%$, and ceftriaxone resistance was reported in $15.2 \%$ of tested isolates. The average risk of SSIs due to ceftriaxone-resistant $E$. coli increased by $37 \%$ annually during the study period.

Of Enterococcus isolates responsible for SSIs, vancomycin resistance was reported in $27.5 \%$ of these cases. A nonsignificant trend toward increased vancomycin resistance in Enterococcus isolates was observed during the study period.

\section{DISCUSSION}

Our findings represent the first detailed evaluation of SSI rates and pathogens responsible for SSIs in Australian patients. S. aureus was the most frequent infecting organism, and a diminishing rate of infection was observed for the majority of pathogens over the 11-year study period. These findings are consistent with international reports that suggest $S$. aureus to be the most frequent infecting organism across a range of surgical procedures, ${ }^{11,19}$ even in the context of reductions in SSI rates for CABGs and orthopedic procedures over the last decade. ${ }^{20,21}$

Contrary to time trends for the majority of pathogens, we observed a significantly increasing incidence of infections due to CNS following CABG procedures and a notable proportion of orthopedic infections (8.9\%) due to CNS. The reasons for these trends are not clear, but some have proposed that infection prevention measures targeting $S$. aureus may not be as effective for reducing risk for CNS SSI and that additional measures (eg, environmental decontamination) may be required to reduce CNS SSI risk. ${ }^{22}$

Antimicrobial-resistant (AMR) pathogens responsible for SSIs displayed significant trends over time. We observed a reduction in infections due to MRSA, recognizing that widespread reductions in bloodstream infections due to S. aureus and $\mathrm{MRSA}^{23}$ and low rates of MRSA nonsurgical wound infection in smaller hospitals ${ }^{24}$ have previously been reported in Victoria. The factors contributing to a reduction in MRSA SSIs are not clear and require further study. We also observed an increasing incidence of ceftriaxone-resistance in E. coli isolates responsible for SSIs. AMR Gram-negative infections, including those due to extended-spectrum $\beta$-lactamase-producing (ESBL) organisms, have increasingly been reported elsewhere over the past decade, ${ }^{19}$ and our findings are consistent with this trend. In contrast, we observed low numbers of carbapenem-resistant isolates responsible for infection, with imipenem resistance reported for only one Pseudomonas isolate. This finding indicates that carbapenem-resistant Enterobacteriacae (CRE) have not 
TA в LE 2. Distribution of Rank Order of Selected Pathogens Responsible for Surgical Site Infections (SSIs) in Victorian Patients, by Procedure Type (2002-2013)

\begin{tabular}{|c|c|c|c|c|c|c|c|c|c|c|c|c|c|c|c|c|c|c|}
\hline \multirow[b]{2}{*}{ Pathogen } & \multicolumn{2}{|l|}{ Overall } & \multicolumn{2}{|c|}{ CABG } & \multicolumn{2}{|c|}{ Caesarean Section } & \multicolumn{2}{|c|}{ Hip/Knee Prosthesis } & \multicolumn{2}{|c|}{ Colorectal } & \multicolumn{2}{|c|}{ Other Adominal } & \multicolumn{2}{|c|}{ Cardiac (Non-CABG) } & \multicolumn{2}{|c|}{ Hysterectomy } & \multicolumn{2}{|c|}{ Vascular } \\
\hline & $\begin{array}{c}\text { No. of } \\
\text { Pathogens } \\
(\%)\end{array}$ & Rank & $\begin{array}{c}\text { No. of } \\
\text { Pathogens } \\
(\%)\end{array}$ & Rank & $\begin{array}{c}\text { No. of } \\
\text { Pathogens } \\
(\%)\end{array}$ & Rank & $\begin{array}{c}\text { No. of } \\
\text { Pathogens } \\
(\%)\end{array}$ & Rank & $\begin{array}{c}\text { No. of } \\
\text { Pathogens } \\
(\%)\end{array}$ & Rank & $\begin{array}{l}\text { No. of } \\
\text { Pathogens } \\
(\%)\end{array}$ & Rank & $\begin{array}{c}\text { No. of } \\
\text { Pathogens } \\
(\%)\end{array}$ & Rank & $\begin{array}{c}\text { No. of } \\
\text { Pathogens } \\
(\%)\end{array}$ & Rank & $\begin{array}{c}\text { No. of } \\
\text { Pathogens } \\
(\%)\end{array}$ & Rank \\
\hline Staphylococ & $1,543(46.5)$ & 1 & $346(41.8)$ & 1 & $247(50.4)$ & 1 & $622(5$ & 1 & $119(28.7)$ & 1 & $55(42.0)$ & 1 & $58(66.7)$ & 1 & $24(36.4)$ & 1 & $19(61.3)$ & 1 \\
\hline Pseudomonas s & $303(9.1)$ & 2 & $76(9.2)$ & 2 & $10(2.0)$ & 6 & $140(11.9)$ & 2 & $58(14.0)$ & 3 & $5(3.8)$ & 3 & $0(0.0)$ & & $6(9.1)$ & 3 & $1(3.2)$ & $4^{c}$ \\
\hline Escherichia coli & $218(6.6)$ & 3 & $39(4.7)$ & 4 & $15(3.1)$ & 2 & $42(3.6)$ & 5 & $86(20.8)$ & 2 & $19(14.5)$ & 2 & $1(1.2)$ & $8^{\mathrm{c}}$ & $10(15.2)$ & 2 & $3(9.7)$ & 2 \\
\hline CNS & $185(5.6)$ & 4 & $49(5.9)$ & 3 & $11(2.2)$ & 5 & $104(8.9)$ & 3 & $3(0.7)$ & d & $3(2.3)$ & 4 & $4(4.6)$ & 2 & $1(1.5)$ & $7^{\mathrm{c}}$ & $0(0.0)$ & \\
\hline Enterococcus spp. ${ }^{\mathrm{e}}$ & $139(4.2)$ & 5 & $21(2.5)$ & 7 & $13(2.7)$ & 3 & $58(4.9)$ & 4 & $33(8.0)$ & 4 & $2(1.5)$ & $5^{\mathrm{c}}$ & $3(3.5)$ & 3 & $4(6.1)$ & 4 & $2(6.5)$ & 3 \\
\hline Enterobacter spp. ${ }^{\mathrm{f}}$ & $65(2.0)$ & 6 & $35(4.2)$ & 5 & $5(1.0)$ & $9^{c}$ & $14(1.2)$ & 9 & $8(1.9)$ & 7 & $1(0.8)$ & d & $1(1.2)$ & $8^{\mathrm{c}}$ & & & $1(3.2)$ & $4^{\mathrm{c}}$ \\
\hline Klebsiella spp. ${ }^{\mathrm{g}}$ & $58(1.8)$ & 7 & $18(2.2)$ & 9 & $5(1.0)$ & $9^{c}$ & $17(1.5)$ & 8 & $9(2.2)$ & 6 & $2(1.5)$ & $5^{c}$ & $3(3.5)$ & $3^{c}$ & $3(4.6)$ & $5^{c}$ & $0(0.0)$ & \\
\hline Proteus mirabilis & $53(1.6)$ & 8 & $20(2.4)$ & 8 & $6(1.2)$ & 8 & $21(1.8)$ & 6 & $0(0.0)$ & b & $1(0.8)$ & & $1(1.2)$ & $8^{\mathrm{c}}$ & $3(4.6)$ & $5^{c}$ & $1(3.2)$ & $4^{\mathrm{c}}$ \\
\hline Serratia marcescens & $50(1.5)$ & 9 & $22(2.7)$ & 6 & $1(0.2)$ & $\mathrm{d}$ & $20(1.7)$ & 7 & $2(0.5)$ & d & $2(1.5)$ & $5^{\mathrm{c}}$ & $3(3.5)$ & $3^{c}$ & $0(0.0)$ & b & $0(0.0)$ & \\
\hline Candida albicans & $34(1.0)$ & 10 & $15(1.8)$ & 10 & $0(0.0)$ & b & $3(0.3)$ & $\mathrm{d}$ & $11(2.7)$ & 5 & $1(0.8)$ & & $2(2.3)$ & 7 & $1(1.5)$ & $7^{\mathrm{c}}$ & $1(3.2)$ & $4^{\mathrm{c}}$ \\
\hline Other & $670(20.2)$ & $\ldots$ & $186(22.5)$ & $\ldots$ & $177(36.1)$ & $\ldots$ & $133(11.3)$ & $\ldots$ & $85(20.5)$ & $\ldots$ & $40(30.5)$ &.. & $11(12.6)$ & $\ldots$ & $14(21.2)$ & $\ldots$ & $3(9.7)$ & . \\
\hline
\end{tabular}

NOTE. CABG, coronary artery bypass graft; CNS, coagulase-negative staphylococci.

${ }^{a}$ Includes Pseudomonas aeruginosa and Pseudomonas spp. not elsewhere classified.

bero SSIs recorded.

${ }^{c}$ Equal ranking with other pathogen(s) for procedure group.

${ }^{\mathrm{d}}$ Not ranked in top 10.

${ }^{\mathrm{e}}$ Includes Enterococcus faecalis, E. faecium and Enterococcus spp. not elsewhere classified.

${ }^{\mathrm{f}}$ Includes Enterobacter cloacae, E. aerogenes and Enterobacter spp. not elsewhere classified.

${ }^{\mathrm{g}}$ Includes Klebsiella pneumoniae and K. oxytoca.

тав ве 3. Modeled Annual Time Trends for Selected Pathogen-Specific Surgical Site Infections (SSIs) in Victorian Patients, by Procedure Type (2002-2013)

\begin{tabular}{|c|c|c|c|c|c|c|c|c|c|}
\hline \multirow[b]{2}{*}{ Pathogen } & \multicolumn{9}{|c|}{ RR $(95 \%$ CI $)$} \\
\hline & Overall & CABG & $\begin{array}{l}\text { Caesarean } \\
\text { Section }\end{array}$ & $\begin{array}{l}\text { Hip/Knee } \\
\text { Prosthesis }\end{array}$ & Colorectal & $\begin{array}{c}\text { Other } \\
\text { Abdominal }\end{array}$ & $\begin{array}{c}\text { Cardiac } \\
\text { (Non-CABG) }\end{array}$ & Hysterectomy & Vascular \\
\hline Staphylococcus aureus & $0.88(0.86-0.89)$ & $0.93(0.90-0.96)$ & $0.86(0.82-0.90)$ & $0.86(0.83-0.88)$ & $0.85(0.80-0.91)$ & $0.96(0.87-1.05)$ & $0.81(0.75-0.88)$ & $0.92(0.81-1.05)$ & $0.86(0.77-0.96)$ \\
\hline Pseudomonas spp. & $0.93(0.89-0.97)$ & $0.98(0.90-1.05)$ & $0.79(0.62-1.00)$ & $0.93(0.88-0.99)$ & $0.88(0.81-0.97)$ & $0.88(0.64-1.21)$ & $\mathrm{a}$ & $1.10(0.81-1.49)$ & $0.50(0.10-2.63)$ \\
\hline Escherichia coli & $0.89(0.85-0.93)$ & $0.85(0.76-0.94)$ & $0.91(0.76-1.09)$ & $0.93(0.84-1.03)$ & $0.85(0.79-0.92)$ & $0.99(0.84-1.17)$ & $0.57(0.26-1.26)$ & $0.91(0.74-1.12)$ & $0.91(0.68-1.21)$ \\
\hline CNS & $0.95(0.91-1.00)$ & $1.14(1.04-1.26)$ & $0.60(0.44-0.82)$ & $0.92(0.86-0.98)$ & $0.80(0.53-1.20)$ & a & a & a & a \\
\hline Enterococcus spp. ${ }^{c}$ & $0.96(0.90-1.01)$ & $0.95(0.82-1.09)$ & $0.73(0.59-0.91)$ & $1.01(0.92-1.11)$ & $0.97(0.86-1.08)$ & $1.05(0.64-1.71)$ & a & a & a \\
\hline Enterobacter spp. ${ }^{\mathrm{d}}$ & $0.93(0.87-1.00)$ & $1.04(0.94-1.14)$ & $0.86(0.68-1.10)$ & $0.88(0.77-1.00)$ & $1.02(0.82-1.26)$ & a & a & a & a \\
\hline
\end{tabular}

NOTE. CABG, coronary artery bypass graft; CNS, coagulase-negative staphylococci; RR, risk ratio; 95\% CI, 95\% confidence interval.

${ }^{a}$ Analysis confined to the 6 most highly-ranked SSI pathogens, excluding indicated instances where insufficient data were available for time-trend analysis.

${ }^{\mathrm{b}}$ Includes Pseudomonas aeruginosa and Pseudomonas spp. not elsewhere classified.

'Includes Enterococcus faecalis, E. faecium and Enterococcus spp. not elsewhere classified.

${ }^{\mathrm{d}}$ Includes Enterobacter cloacae, E. aerogenes and Enterobacter spp. not elsewhere classified. 
т AвLE 4. Antibiotic Resistance and Modelled Annual Time Trends for Selected Pathogens Responsible for Surgical Site Infections (SSIs) in Victorian Patients (2002-2013)

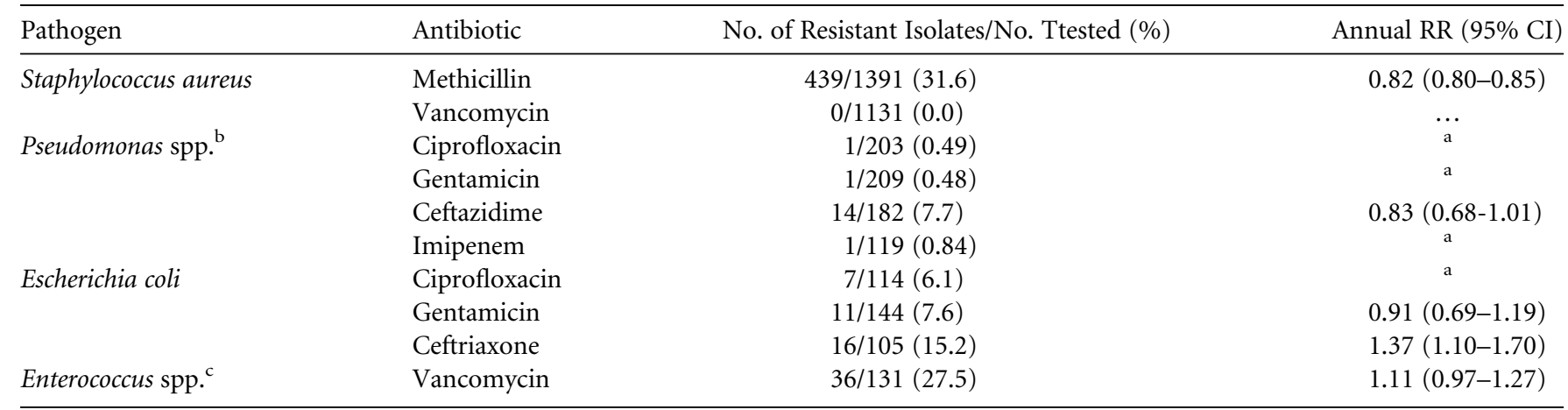

NOTE. RR, risk ratio; 95\% CI, 95\% confidence interval.

${ }^{a}$ Insufficient data available for time-trend analysis.

${ }^{\mathrm{b}}$ Includes Pseudomonas aeruginosa and Pseudomonas spp. not classified elsewhere.

${ }^{\mathrm{c}}$ Includes Enterococcus faecalis, E. faecium and Enterococcus spp. not classified elsewhere.

contributed significantly to SSI trends to date in Victoria and is quite different from findings reported in Japan ${ }^{19}$ and the United States, ${ }^{25}$ where CRE have emerged as significant pathogens. The observed low rate of ciprofloxacin resistance in E. coli isolates responsible for SSIs is consistent with restricted use of fluoroquinolone agents in Australia. ${ }^{26}$ Ongoing targeted surveillance is required in Victoria to ensure that emerging resistant pathogens are detected in a timely manner. A trend toward an increased proportion of Enterococci with vancomycin resistance (VRE) was observed during the study period, likely a reflection of VRE emerging as endemic in many Victorian centers. ${ }^{27,28}$

These findings are relevant to recommendations for antimicrobial prophylaxis prior to surgical procedures. It is appropriate to target a broad spectrum of likely SSI pathogens in settings in which SSI rates are high or in settings in which SSI rates are low but catastrophic consequences would result from infection (eg, sternal wound infections following CABG procedures). Review of pathogens responsible for SSIs is necessary in the formulation of local guidelines for antibiotic prophylaxis. For example, we identified $>13 \%$ of SSIs following colorectal procedures to be due to MRSA. Current national guidelines do not recommend the use of prophylactic antibiotic agents with anti-MRSA activity. ${ }^{12}$ While the use of vancomycin prophylaxis may need to be considered, preoperative MRSA screening and decolonization may be more appropriate, given the potential for routine vancomycin administration to contribute to further increases in already rising rates of SSI due to VRE in our region. This approach is consistent with international consensus guidelines. ${ }^{29}$

Risk-adjustment is necessary for reporting SSI surveillance data, ${ }^{30}$ and we applied risk-indexing according to criteria established by the NHSN/CDC (Table 1$).{ }^{17}$ These data confirm that crude SSI rates do not reliably reflect trends or enable interhospital comparison. ${ }^{31}$ For CABG and orthopedic procedures, although our crude SSI rates were similar to adjusted rates for risk index category 1 , a large number of patients were classified as risk index category 2 , where SSI rates were $\sim 50 \%$ higher. A crude rate would not adequately convey this increase in risk. Increasingly, the standardized infection ratio (SIR) is used for adjustment of hospital-level data, ${ }^{32,33}$ despite criticisms that this may be an over-simplification and not a meaningful indicator of infection prevention initiatives implemented in specialized surgical units. ${ }^{34}$ Looking ahead, we believe that SIR may hold merit for reporting Victorian data, provided the required data elements can be feasibly collected by participating centers.

Limitations of this study include the fact that surveillance activities were not performed continuously in all participating hospitals. Orthopedic and CABG surveillance were performed continuously, but reporting of other procedures may have occurred periodically at some centers. For example, crude SSI rates for vascular surgical procedures were high. Although this finding is comparable to rates reported elsewhere, ${ }^{35}$ periodic surveillance was performed for these procedures, and the potential for ascertainment bias must also be considered. Notwithstanding this limitation, our strategy encompassed all public hospitals in Victoria, and our data are very likely to reflect trends in the region. Secondly, factors potentially responsible for diminishing SSI rates were not evaluated. It is well-recognized that reductions in HAIs are observed following commencement of formal surveillance activities. ${ }^{36}$ For the current study, SSI risk-reduction strategies potentially contributing to time trends, such as hospital infection prevention practices ${ }^{37}$ or use of appropriate surgical antibiotic prophylaxis, ${ }^{38}$ were not analyzed. Thirdly, pathogen-specific data were insufficient to permit modeling by surgical risk category. A larger national dataset would allow more detailed analyses. Furthermore, recording of pathogen and antimicrobial susceptibility was reliant upon availability of laboratory reports to infection prevention staff. Our data may therefore underestimate antimicrobial resistance. Looking ahead, this process could be refined by automated extraction of laboratory data. 
Finally, rare but significant events were not captured (eg, molecular mechanisms of antimicrobial resistance). A national, laboratory-based surveillance system would more appropriately meet this need.

In summary, internationally accepted SSI surveillance methods have been successfully and sustainably implemented in Victoria, Australia. Over an 11-year period, a diminishing rate of SSI was observed for the majority of pathogens responsible for SSIs, although infections due to ceftriaxoneresistant $E$. coli increased significantly. National standardized SSI data would enable timely identification of changes in epidemiology, ${ }^{39}$ particularly time trends in risk-adjusted data and rare but significant events.

\section{A C KNOW LEDGMENTS}

The authors acknowledge the infection prevention consultants in participating Victorian hospitals for the collection and submission of data.

Financial support: The VICNISS Coordinating Centre is funded by the Victorian Department of Health.

Potential conflicts of interest: All authors report no conflict of interest or financial disclosures.

Address correspondence to Associate Professor Leon J. Worth, Victorian Healthcare Associated Infection Surveillance System (VICNISS) Coordinating Centre, Doherty Institute, 792 Elizabeth Street, Melbourne, Victoria, 3000, Australia (leon.worth@mh.org.au).

\section{REFERENCES}

1. Shepard J, Ward W, Milstone A, et al. Financial impact of surgical site infections on hospitals: the hospital management perspective. JAMA Surg 2013;148:907-914.

2. Agency HP. Surveillance of surgical site infections in NHS hospitals in England, 2011/2012.www.hpa.org.uk. Published December 2012. Accessed August 1, 2013.

3. Edwards JR, Peterson KD, Andrus ML, Dudeck MA, Pollock DA, Horan TC. National Healthcare Safety Network (NHSN) Report, data summary for 2006 through 2007, issued November 2008. Am J Infect Control 2008;36:609-626.

4. Itani KM, Wilson SE, Awad SS, Jensen EH, Finn TS, Abramson MA. Ertapenem versus cefotetan prophylaxis in elective colorectal surgery. N Engl J Med 2006;355:2640-2651.

5. Sergeant G, Buffet W, Fieuws S, de Gheldere C, Vanclooster P. Incisional surgical site infections after colorectal surgery: time to appraise its true incidence. Acta Chir Belg 2008;108:513-517.

6. Smith RL, Bohl JK, McElearney ST, et al. Wound infection after elective colorectal resection. Ann Surg 2004;239:599-605; discussion 605-607.

7. Geubbels EL, Nagelkerke NJ, Mintjes-De Groot AJ, Vandenbroucke-Grauls CM, Grobbee DE, De Boer AS. Reduced risk of surgical site infections through surveillance in a network. Int J Qual Health Care 2006;18:127-133.

8. German RR, Lee LM, Horan JM, Milstein RL, Pertowski CA, Waller MN. Updated guidelines for evaluating public health surveillance systems: recommendations from the Guidelines Working Group. MMWR Recom Rep 2001;50:1-35; quiz CE1-7.

9. Diaz-Agero Perez C, Robustillo Rodela A, Pita Lopez MJ, Lopez Fresnena N, Monge Jodra V. Surgical wound infection rates in
Spain: data summary, January 1997 through June 2012. Am J Infect Control 2014;42:521-524.

10. Brandt C, Sohr D, Behnke M, Daschner F, Ruden H, Gastmeier P. Reduction of surgical site infection rates associated with active surveillance. Infect Control Hosp Epidemiol 2006;27: 1347-1351.

11. Berrios-Torres SI, Yi SH, Bratzler DW, et al. Activity of commonly used antimicrobial prophylaxis regimens against pathogens causing coronary artery bypass graft and arthroplasty surgical site infections in the United States, 2006-2009. Infect Control Hosp Epidemiol 2014;35:231-239.

12. Antibiotic Expert Group. Therapeutic guidelines: antibiotic. Version 14. Melbourne: Therapeutic Guidelines Limited, 2010.

13. Russo PL, Bull A, Bennett N, et al. Infections after coronary artery bypass graft surgery in Victorian hospitals-VICNISS Hospital Acquired Infection Surveillance. Aust N Z J Public Health 2005;29:244-248.

14. Friedman ND, Russo PL, Bull AL, Richards MJ, Kelly H. Validation of coronary artery bypass graft surgical site infection surveillance data from a statewide surveillance system in Australia. Infect Control Hosp Epidemiol 2007;28:812-817.

15. Russo PL, Bull A, Bennett N, et al. The establishment of a statewide surveillance program for hospital-acquired infections in large Victorian public hospitals: a report from the VICNISS Coordinating Centre. Am J Infect Control 2006;34:430-436.

16. Centers for Diseases Control and Prevention. The National Healthcare Safety Network (NHSN) Patient Safety Component Manual. www.cdc.gov/nhsn/PDFs/pscManual/PSC-Manual-portfolio. pdf. Published July 2013. Accessed August 1, 2013.

17. Horan TC, Culver DH, Gaynes RP, Jarvis WR, Edwards JR, Reid CR. Nosocomial infections in surgical patients in the United States, January 1986-June 1992. National Nosocomial Infections Surveillance (NNIS) System. Infect Control Hosp Epidemiol 1993;14:73-80.

18. Friedman ND, Bull AL, Russo PL, Gurrin L, Richards M. Performance of the national nosocomial infections surveillance risk index in predicting surgical site infection in Australia. Infect Control Hosp Epidemiol 2007;28:55-59.

19. Takesue $Y$, Watanabe A, Hanaki H, et al. Nationwide surveillance of antimicrobial susceptibility patterns of pathogens isolated from surgical site infections (SSI) in Japan. J Infect Chemother 2012;18:816-826.

20. Alasmari FA, Tleyjeh IM, Riaz M, et al. Temporal trends in the incidence of surgical site infections in patients undergoing coronary artery bypass graft surgery: a population-based cohort study, 1993 to 2008. Mayo Clin Proc 2012;87:1054-1061.

21. Skramm I, Saltyte Benth J, Bukholm G. Decreasing time trend in SSI incidence for orthopaedic procedures: surveillance matters! J Hosp Infect 2012;82:243-247.

22. Yavuz SS, Tarcin O, Ada S, et al. Incidence, aetiology, and control of sternal surgical site infections. J Hosp Infect 2013;85:206-212.

23. Worth LJ, Spelman T, Bull AL, Richards MJ. Staphylococcus aureus bloodstream infection in Australian hospitals: findings from a Victorian surveillance system. Med J Aust 2014;200:282-284.

24. Bennett NJ, Bull AL, Dunt DR, et al. MRSA infections in smaller hospitals, Victoria, Australia. Am J Infect Control 2007;35: 697-699.

25. Sievert DM, Ricks P, Edwards JR, et al. Antimicrobial-resistant pathogens associated with healthcare-associated infections: summary 
of data reported to the National Healthcare Safety Network at the Centers for Disease Control and Prevention, 2009-2010. Infect Control Hosp Epidemiol 2013;34:1-14.

26. Cheng AC, Turnidge J, Collignon P, Looke D, Barton M, Gottlieb T. Control of fluoroquinolone resistance through successful regulation, Australia. Emerg Infect Dis 2012;18:1453-1460.

27. Worth LJ, Slavin MA, Vankerckhoven V, Goossens H, Grabsch EA, Thursky KA. Virulence determinants in vancomycin-resistant Enterococcus faecium vanB: clonal distribution, prevalence and significance of esp and hyl in Australian patients with haematological disorders. J Hosp Infect 2008;68:137-144.

28. Johnson PD, Ballard SA, Grabsch EA, et al. A sustained hospital outbreak of vancomycin-resistant Enterococcus faecium bacteremia due to emergence of vanB E. faecium sequence type 203. J Infect Dis 2010;202:1278-1286.

29. Bratzler DW, Dellinger EP, Olsen KM, et al. Clinical practice guidelines for antimicrobial prophylaxis in surgery. Am J Health Syst Pharm 2013;70:195-283.

30. Worth LJ, Bull AL, Richards MJ. Public reporting of health care-associated infection data in Australia: time to refine. Med J Aust 2013;198:252-253.

31. van Dishoeck AM, Koek MB, Steyerberg EW, van Benthem BH, Vos MC, Lingsma HF. Use of surgical-site infection rates to rank hospital performance across several types of surgery. Br J Surg 2013;100:628-636; discussion 637.
32. Rioux C, Grandbastien B, Astagneau P. The standardized incidence ratio as a reliable tool for surgical site infection surveillance. Infect Control Hosp Epidemiol 2006;27:817-824.

33. Gustafson TL. Three uses of the standardized infection ratio (SIR) in infection control. Infect Control Hosp Epidemiol 2006;27: 427-430.

34. Birnbaum D, Zarate R, Marfin A. SIR, you've led me astray!. Infect Control Hosp Epidemiol 2011;32:276-282.

35. Pounds LL, Montes-Walters M, Mayhall CG, et al. A changing pattern of infection after major vascular reconstructions. Vasc Endovascular Surg 2005;39:511-517.

36. Gastmeier P, Schwab F, Sohr D, Behnke M, Geffers C. Reproducibility of the surveillance effect to decrease nosocomial infection rates. Infect Control Hosp Epidemiol 2009;30:993-999.

37. Bull A, Wilson J, Worth LJ, et al. A bundle of care to reduce colorectal surgical infections: an Australian experience. J Hosp Infect 2011;78:297-301.

38. Bull AL, Russo PL, Friedman ND, Bennett NJ, Boardman CJ, Richards MJ. Compliance with surgical antibiotic prophylaxisreporting from a statewide surveillance programme in Victoria, Australia. J Hosp Infect 2006;63:140-147.

39. Worth LJ, Bull AL, Thorpe SM, Richards MJ. Meeting national recommendations for surgical site infection surveillance: examples and lessons from the Victorian Healthcare-associated Infection Surveillance System. Healthcare Infect 2009;14:119-122. 